\title{
Effect of polymorphisms of the MTHRR and APOE genes on susceptibility to diabetes and severity of diabetic retinopathy in Brazilian patients
}

F.I.V. Errera1,5, M.E.R. Silva ${ }^{5}$, E. Yeh ${ }^{1}$, C.M.C. Maranduba ${ }^{1}$, B. Folco ${ }^{3}$, W. Takahashi3, A.C. Pereira ${ }^{4}$, J.E. Krieger ${ }^{4}$ and M.R. Passos-Bueno ${ }^{1}$

\author{
${ }^{1}$ Centro de Estudos do Genoma Humano, Instituto de Biociências, \\ ${ }^{2}$ Departamento de Endocrinologia, ${ }^{3}$ Departamento de O ftalmologia, \\ ${ }^{4}$ Laboratório de Genética e Cardiologia Molecular, Instituto do Coração, \\ Faculdade de Medicina, Universidade de São Paulo, São Paulo, SP, Brasil \\ ${ }^{5}$ Escola Superior de Ciências da Santa Casa de Misericórdia, Vitória, ES, Brasil
}

\section{Correspondence \\ M.R. Passos-Bueno \\ Departamento de Biologia \\ Instituto de Biociências, USP \\ Rua do Matão, 277 \\ 05508-900 São Paulo, SP \\ Brasil \\ Fax: +55-11-3091-7419 \\ E-mail: passos@ib.usp.br}

Research supported by FAPESP/CEPID and CNPq.

Received August 9, 2005

Accepted March 27, 2006

\section{Abstract}

Diabetes mellitus (DM) is a highly prevalent complex genetic disorder. There has been a worldwide effort in the identification of susceptibility genes for DM and its complications, and the 5-10-methylenetetrahydrofolate reductase (MTHFR) and apolipoprotein-E (APOE) genes have been considered good candidate susceptibility genes to this condition. The objectives of the present study were to determine if the 677T MTHFR and $\varepsilon 2 / \varepsilon 3 / \varepsilon 4 A P O E$ alleles are risk factors for DM and for severity of diabetic retinopathy (DR). A total of 248 individuals were studied: 107 healthy individuals and 141 diabetic patients (46 with type 1 diabetes and 95 with type 2 diabetes), who also had DR (81 with non-proliferative DR and 60 with proliferative DR). The polymorphisms were analyzed by PCR followed by digestion with restriction enzyme or the single-nucleotide primer extension method. No evidence of association between the 677TT genotype of MTHFR gene and DM [cases: TT $=10 / 95(10.6 \%)$; controls: TT $=14 / 107(13 \%)]$ or with severity of DR was observed [cases: $\mathrm{TT}=5 / 60(8.5 \%)$; controls: $\mathrm{TT}=9 / 81(11.1 \%) ; \mathrm{P}>0.05]$. We also did not find evidence of an association between $A P O E$ alleles and proliferative DR ( $(22, \varepsilon 3$ and $\varepsilon 4$ in cases: 9,76 , and $15 \%$, and in controls: 5,88 , and $12 \%$, respectively) but the carriers of $\varepsilon 2$ allele were more frequent among patients with type 2 DM and DR than in controls [cases: 15/95 (15.8\%); controls: 7/ 107 (6.5\%); $\mathrm{P}<0.05]$. Therefore, our results suggest that the $\varepsilon 2$ allele/ $A P O E$ might be a risk factor for diabetes in the Brazilian population.

\section{Introduction}

Diabetes is a highly prevalent complex disorder characterized by increased blood glucose levels. An autoimmune process destroys $\beta$-cells in type 1 diabetes mellitus

\author{
Key words \\ - APOE \\ - MTHFR \\ - Polymorphisms \\ - Diabetes \\ - Diabetic retinopathy
}

(DM1), whereas a combination of genetic and environmental factors brings about Bcell failure in type $2 \mathrm{DM}$ (DM2), resulting in impaired action and secretion of insulin (1). The prevalence of DM in the population aged 30-69 years was 7.6\% in the Brazilian 
Multicenter Study (2), which is comparable to European $(8.8 \%)$ and USA $(7.3 \%)$ data (2). The leading causes of morbidity and mortality in diabetic patients are the microand macrovascular complications (3).

Diabetic retinopathy (DR) is one of the major microvascular complications of diabetes. Clinical studies on subjects with DM have revealed substantial variation in the onset and severity of DR that is not fully explained by the known risk factors such as duration of DM and level of glycemic control. Furthermore, the risk of severe DR among the siblings of affected individuals is substantially increased $(4,5)$, suggesting that genetic influences are operating in DR.

The identification of susceptibility genes associated with complex disorders has been a difficult task and case-control studies have been one of the approaches most frequently used. A large number of candidate genes have been examined in case-control studies, and a few of these studies have been carried out in more than one population (6). It is also of interest to identify genes involved in the severity of diabetes complications. Genes that play a role in vascular homeostasis, such as 5-10-methylenetetrahydrofolate reductase $(M T H F R)$ and apolipoprotein-E (APOE), have been considered to be good candidates both for susceptibility to diabetes and for severity of the disease and its complications (7).

The c.677C $>\mathrm{T}$ polymorphism in the MTHFR gene, which encodes an enzyme involved in remethylation of homocysteine to methionine, leads to increased thermolability and impaired enzymatic activity. It is the most common genetic determinant of moderate hyperhomocystinemia, a risk factor for vascular disease. The 677T/MTHFR allele has also been associated with nephropathy and DR $(8,9)$; however, the validity of these associations is still controversial (10$12)$.

The most studied functional polymorphisms of $A P O E$ are the $\varepsilon 2, \varepsilon 3$ and $\varepsilon 4$ alleles, which differ by single-amino acid substitu- tions. The $\varepsilon 3$ allele is the most frequent, representing 74 to $86 \%$ of all alleles, the frequency of the $\varepsilon 4$ allele is approximately 7 to $16 \%$ and the frequency of the $\varepsilon 2$ allele is 6.3 to $12 \%$ in European and American Caucasian populations (13-15). The allelic variation at the $A P O E$ locus contributes to lipid profile variation and has been suggested to be a risk factor for the development of micro- and macrovascular complications in diabetic patients in several studies, but not in all populations (16). There are, however, very few studies of this polymorphic system in DR, particularly for DM2 (17-19).

At-risk susceptibility genes might play a role in causing the disease depending on the population, and the molecular characterization of these genes is of the utmost importance in every population. Thus, the purposes of the present study were to determine if the $677 \mathrm{~T}$ allele in the MTHFR gene and the $\varepsilon 2, \varepsilon 3, \varepsilon 4$ alleles in the $A P O E$ gene play a role in the predisposition to DM and in the severity of DR in the Brazilian population.

\section{Subjects and Methods}

\section{Subjects}

A total of 248 individuals were identified at Hospital das Clínicas, Faculdade de Medicina, São Paulo University (HC, FM, USP): 107 were control individuals (90 individuals of European-Brazilian descent and 17 individuals of African-Brazilian descent) with no DM or hypertension with a mean age of $66.11 \pm 7.06$ years and 141 were diabetic patients (46 with DM1 and 95 with DM2; 105 of European-Brazilian descent and 36 of African-Brazilian descent) with a mean age of $55.43 \pm 15.33$ years. The ethnic classification as European-Brazilian and AfricanBrazilian was based on phenotype (hair color, type and conformation of the nose and lips) and family history (20). The diagnosis of diabetes was based on clinical features, laboratory data and the guidelines of the Ameri- 
can Diabetes Association (21). Onset and duration of the disease were determined on the basis of the date of clinical diagnosis definition. Clinical and laboratory data were collected retrospectively and the average of the measurements made during 1997-2001 was considered. The main clinical features of the patients are summarized in Table 1 . Most of patients were taking lipid-lowering drugs and therefore the lipid profile could not be used in genotype-phenotype correlation analysis.

Assessment of DR was performed by fundus ophthalmoscopy and biomicroscopy by a retinal specialist; fluorescein angiography was obtained in some cases when indicated. DR was classified according to the International Clinical Diabetic Retinopathy Disease Severity Scale (22) as: non-proliferative DR (NPDR) and proliferative DR (PDR). NPDR denotes signs of microaneurysms, intraretinal hemorrhage, exudates, macular edema, venous dilatation, soft exudates, peripheral ischemia, intraretinal microvascular abnormalities, and diffuse intraretinal hemorrhage. PDR denotes signs of neovascularization in the optic disc and elsewhere, vitreous hemorrhage, and fibrovascular proliferation. Of the 141 diabetic patients, 81 were non-PDR and 60 were PDR. Blood was drawn only after approval of the protocol by the local Ethics Committee. Each patient gave written informed consent.

\section{Molecular and statistical analysis}

DNA was isolated from whole peripheral blood samples by standard techniques (23). Genotyping of MTHFR gene polymorphism was carried out by PCR using primers and amplification conditions reported elsewhere (24), followed by a single-nucleotide primer extension assay (primer 5'-3': GCTGCGTGA TGATGAAATCG) analyzed by Megabace (Amersham-Biosciences Pharmacia Biotech Inc., Piscataway, NJ, USA). The different alleles of the $A P O E$ were detected according to published protocols (25).

The distribution of genotypes and alleles was compared by the chi-square $\left(\chi^{2}\right)$ or Fisher exact test. Hardy-Weinberg equilibrium was also verified in all samples. The level of significance adopted was $5 \%$. The proportion of European-Brazilian and African-Brazilian descendants was the same in the subgroups analyzed.

\section{Results}

\section{Characterization of the sample}

A total of 248 individuals were included in the study: 107 healthy individuals and 141 diabetic patients (46 with DM1 and 95 with DM2). All patients had DR (81 with NPDR and 60 with PDR).

\section{Genotype analysis}

The distribution of the genotypes for the $677 \mathrm{~T}>\mathrm{C} / M T H F R$ and the $\varepsilon 2 / \varepsilon 3 / \varepsilon 4 / A P O E$ polymorphisms are summarized in Table 2.

Table 1. Main clinical and laboratory data of diabetic patients.

\begin{tabular}{lccc}
\hline & All & NPDR & PDR \\
\hline Number & 141 & 81 & 60 \\
Gender (F:M) & $87: 54$ & $54: 27$ & $33: 27$ \\
European:African & $105: 36$ & $61: 20$ & $44: 16$ \\
$\quad$ Brazilian individuals & & & \\
Age (years) & $55.43 \pm 15.33$ & $56.37 \pm 15.35$ & $53.76 \pm 15.25$ \\
Age at onset (years) & $37 \pm 17.86$ & $39 \pm 18.2$ & $36 \pm 17.3$ \\
Duration of DM (years) & $18 \pm 8.67$ & $18 \pm 8.97$ & $19 \pm 8.24$ \\
DM1:DM2 (proportion) & $46: 95$ & $24: 57$ & $22: 38$ \\
BMI (kg/m2) & $26 \pm 5.21$ & $26.18 \pm 5.95$ & $25.84 \pm 4.13$ \\
GHb (\%) & $10.22 \pm 2.20$ & $10.1 \pm 1.95$ & $10.35 \pm 2.53$ \\
Cholesterol (mg/dL) & $206.2 \pm 51.17$ & $206.92 \pm 49$ & $205.21 \pm 54.70$ \\
LDL (mg/dL) & $127 \pm 42$ & $127.16 \pm 41$ & $126.84 \pm 43.7$ \\
HDL (mg/dL) & $49.6 \pm 13.9$ & $49.99 \pm 13.76$ & $49.06 \pm 14.43$ \\
Triglycerides (mg/dL) & $142.8 \pm 98.95$ & $148.81 \pm 112.9$ & $134.64 \pm 76.19$ \\
Creatinine (mg/dL) & $1.55 \pm 1.65$ & $1.23 \pm 1.19$ & $1.86 \pm 2.08$ \\
Insulin therapy & $68.2 \%$ & $57.3 \%$ & $81.8 \%$ \\
Nephropathy & $56(39.7 \%)$ & $30(37.0 \%)$ & $26(43.3 \%)$ \\
& & &
\end{tabular}

Data are reported as number of patients, means $\pm S D$, proportion, or percent when indicated. NPDR = non-proliferative diabetic retinopathy; PDR = proliferative diabetic retinopathy; $\mathrm{DM} 1$ = type 1 diabetes; DM2 = type 2 diabetes; $\mathrm{BMI}=$ body mass index; $\mathrm{GHb}=$ glycated hemoglobin. 
Genotype frequencies were in Hardy-Weinberg equilibrium in both polymorphic systems (MTHFR: controls $\mathrm{P}=0.31$ and patients $\mathrm{P}=0.57$; $A P O E$ : controls $\mathrm{P}=0.50$ and patients $\mathrm{P}=0.87$ ). Homozygotes for allele $\varepsilon 2$ and $\varepsilon 4$ were not observed in this sample.

In order to evaluate the effect of the genotypes on the severity of retinopathy we pooled the patients with DM1 and DM2 since development of DR is considered to be a consequence of the hyperglycemic state rather than a result of the underlying cause of diabetes (26-28).

The genotypic and allelic frequencies for the 677 T/MTHFR allele were similar in all subgroups, with no evidence of association between this polymorphism and diabetes or severity of DR (DM1 vs controls: $\chi^{2}=0.62$, d.f. $=2, \mathrm{P}=0.73$; DM2 vs controls: $\chi^{2}=3.37$, d.f. $=2, \mathrm{P}=0.18$; NPDR $v s$ PDR: $\chi^{2}=0.62$, d.f. $=2, \mathrm{P}=0.73$ ).

The allelic and genotypic frequencies for

Table 2. Genotype and allele distribution of MTHFR and APOE polymorphisms in diabetic patients with retinopathy and controls.

\begin{tabular}{|c|c|c|c|c|c|}
\hline Polymorphism & Control & NPDR & PDR & DM 1 & DM2 \\
\hline Number & 107 & 81 & 60 & 46 & 95 \\
\hline \multicolumn{6}{|l|}{ MTHFR } \\
\hline CC & $36(33.8)$ & $33(40.7)$ & $28(46.7)$ & $17(37)$ & $44(46.3)$ \\
\hline $\mathrm{CT}$ & $57(53.2)$ & $39(48.2)$ & $27(45)$ & $25(54.3)$ & $41(43.1)$ \\
\hline TT & $14(13)$ & 9 (11.1) & $5(8.3)$ & $4(8.7)$ & $10(10.6)$ \\
\hline \multicolumn{6}{|l|}{ Alleles } \\
\hline C & 0.60 & 0.65 & 0.69 & 0.64 & 0.68 \\
\hline T & 0.40 & 0.35 & 0.31 & 0.36 & 0.32 \\
\hline \multicolumn{6}{|l|}{ APOE } \\
\hline \multicolumn{6}{|l|}{ Genotypes } \\
\hline$\varepsilon 2 \varepsilon 3$ & $7(6.5)$ & $8(9.9)$ & $9(15)$ & $4(4.5)$ & $13(13.7)$ \\
\hline$\varepsilon 2 \varepsilon 4$ & - & $1(1.2)$ & $2(3.4)$ & $1(4.5)$ & $2(2.1)$ \\
\hline$\varepsilon 3 \varepsilon 3$ & 77 (71.9) & $59(72.9)$ & $35(58.3)$ & $27(59.2)$ & $68(71.6)$ \\
\hline$\varepsilon 3 \varepsilon 4$ & $23(21.4)$ & $13(16)$ & $14(23.3)$ & $14(31.8)$ & 12 (12.6) \\
\hline \multicolumn{6}{|l|}{ Alleles } \\
\hline$\varepsilon 2$ & 0.03 & 0.05 & 0.09 & 0.05 & 0.08 \\
\hline$\varepsilon 3$ & 0.86 & 0.88 & 0.76 & 0.79 & 0.85 \\
\hline$\varepsilon 4$ & 0.11 & 0.12 & 0.15 & 0.16 & 0.07 \\
\hline
\end{tabular}

Data are reported as number of patients and percent in parentheses. NPDR $=$ nonproliferative diabetic retinopathy; $P D R=$ proliferative diabetic retinopathy; $D M 1=$ type 1 diabetes; DM2 = type 2 diabetes. the $\varepsilon 2 / \varepsilon 3 / \varepsilon 4$ polymorphisms of $A P O E$ were not significantly different according to severity of retinopathy (NPDR $v s$ PDR: $\chi^{2}=$ 3.50 , d.f. $=3, \mathrm{P}=0.31$ ). Due to the low frequency of the $\varepsilon 2 / \varepsilon 4$ genotype, individuals were divided into a group of carriers of the $\varepsilon 2$ allele ( $\varepsilon 2 / \varepsilon 3$ and $\varepsilon 2 / \varepsilon 4$ genotypes) and a group of non-carriers of the $\varepsilon 2$ allele $(\varepsilon 3 / \varepsilon 3$ and $\varepsilon 3 / \varepsilon 4$ genotypes) for statistical analysis. In this comparison, an association between $A P O E$ allele $\varepsilon 2$ and DM2 was observed with a borderline level of significance $(\mathrm{P}=0.04$, $\mathrm{OR}=2.67: 1.0-6.88$ ).

\section{Discussion}

In the present study, we did not find any evidence of association between the 677T MTHFR allele and DM or DR, in agreement with some reports of the literature $(10,11)$, including one in the Brazilian population in which all DR patients were of European ancestry (12). We believe that ethnicity did not lead to false-negative results, since similar results were observed after exclusion of the African-Brazilian descendants both from the control and patient's samples (the frequency of genotype TT was $15 \%$ (14/90) in the control group and 10\% (10/105) in the patient group). It is important to note that the frequency of homozygotes for the $677 \mathrm{~T}$ allele observed in our group of diabetic patients was comparable with the TT genotype frequency previously estimated in other ethnically mixed healthy populations of São Paulo and Ceará $(29,30)$.

Maeda et al. (31) analyzed their data taking into account glycemic control and suggested that $677 \mathrm{~T} /$ MTHFR might be a susceptibility locus for DR in individuals with poor glycemic control. If this hypothesis is correct, a significantly higher frequency of the TT genotype should have been an obligatory finding in the sample reported here, since the majority of our patients (112/ 141) had high glycated hemoglobin (GHb; $>8.5 \%$ ). Therefore, our data further support 
that the $677 \mathrm{~T} / M T H F R$ polymorphism is not a predictive marker for DM or DR.

The APOE gene has been extensively studied in several diseases around the world (32). In Brazil, it has been more explored in Alzheimer's disease $(14,15)$ and we are not aware of any genetic studies of $A P O E$ in diabetes or its complications in our population. The genotypic and allelic frequencies of the $A P O E$ polymorphic system in our control sample were similar to those of the control population of São Paulo (15). In the present study, we did not find evidence of an association between $A P O E$ alleles and the severity of retinopathy in either DM1 or DM2, in agreement with other reports $(17,18)$.

We also did not find an association between $A P O E$ and DM1 in this sample. Although the lack of association may have been due to the small sample size, it is very likely that these alleles do not play a major role in the genetic predisposition to this type of diabetes. On the other hand, we observed an increased frequency of the $\varepsilon 2$ allele among patients with DM2. Considering that all the DM2 patients had retinopathy, we cannot yet generalize this finding to DM2 without complications.

This positive association of allele $\varepsilon 2 /$ $A P O E$ with DM2 is in agreement with data from the literature, which points to the involvement of allele $\varepsilon 2 / A P O E$ in the occurrence of DM2 (33) or in diabetic nephropathy (34-36). We could speculate that our positive results were due to the simultaneous occurrence of DM and nephropathy; however, the frequency of the $\varepsilon 2 / A P O E$ allele was similar $(\varepsilon 2=13 / 190=6.8 \%)$ in patients with and without nephropathy $(\varepsilon 2=7 / 112=$ $6.1 \%)$, implying that the higher frequency of the $\varepsilon 2 / A P O E$ allele might be primarily related to DM2. A possible mechanism to explain this association is that the increased triglyceride levels observed in the presence of the $\varepsilon 2$ allele $(37,38)$ can be a predisposing factor to insulin resistance and consequently to DM2 (39).

In summary, our data confirm reports that the $677 \mathrm{C}>\mathrm{T} / \mathrm{MTHFR}$ allele does not play an important role in the severity of DR. In contrast, the $\varepsilon 2 / A P O E$ allele seems to be a predisposing factor to DM2 but not to severity of DR. This result should be confirmed in a larger sample and indicates the need to further investigate $A P O E$ in patients with DM2 in the Brazilian population.

\section{Acknowledgments}

We thank all of the patients and volunteers who participated in the study and also the following persons: Dr. Daniel GianellaNeto of HC/FMUSP of São Paulo, Ms. Agnes L. Nishmura for helping in the genotype analysis and Mrs. Constância G. Urbani for secretarial assistance at the Department of Genetics and Evolution Biology, Institute of Biosciences, University of São Paulo, São Paulo, SP, Brazil.

\section{References}

1. Saltiel AR. New perspectives into the molecular pathogenesis and treatment of type 2 diabetes. Cell 2001; 104: 517-529.

2. Malerbi DA, Franco LJ . Multicenter study of the prevalence of diabetes mellitus and impaired glucose tolerance in the urban Brazilian population aged 30-69 yr. The Brazilian Cooperative Group on the Study of Diabetes Prevalence. Diabetes Care 1992; 15: 1509-1516.

3. National Diabetes Data Group. Diabetes in America. Bethesda: National Institute of Diabetes and Digestive and Kidney Diseases; 1995.
4. Leslie RD, Pyke DA. Diabetic retinopathy in identical twins. Diabetes 1982; 31: 19-21.

5. Rema M, Saravanan G, Deepa R, Mohan V. Familial clustering of diabetic retinopathy in South Indian type 2 diabetic patients. Diabet Med 2002; 19: 910-916.

6. Cardon LR, Bell JI. Association study designs for complex diseases. Nat Rev Genet 2001; 2: 91-99.

7. Warpeha KM, Chakravarthy U. Molecular genetics of microvascular disease in diabetic retinopathy. Eye 2003; 17: 305-311. 
8. Neugebauer S, Baba T, Watanabe T. Methylenetetrahydrofolate reductase gene polymorphism as a risk factor for diabetic nephropathy in NIDDM patients. Lancet 1998; 352: 454.

9. Maeda M, Yamamoto I, Fukuda M, Nishida M, Fujitsu J, Nonen S, et al. MTHFR gene polymorphism as a risk factor for diabetic retinopathy in type 2 diabetic patients without serum creatinine elevation. Diabetes Care 2003; 26: 547-548.

10. Fujita $H$, Narita $T$, Meguro $H$, Ishii $T$, Hanyu O, Suzuki K, et al. No association between MTHFR gene polymorphism and diabetic nephropathy in Japanese type II diabetic patients with proliferative diabetic retinopathy. J Diabetes Complications 1999; 13: 284-287.

11. Yoshioka K, Yoshida T, Takakura Y, Kogure A, Umekawa T, Toda $H$, et al. No association between the MTHFR gene polymorphism and diabetic retinopathy in type 2 diabetic patients without overt nephropathy: response to Maeda et al. Diabetes Care 2003; 26: 1947-1948.

12. Santos KG, Tschiedel B, Schneider J, Souto K, Roisenberg I. Diabetic retinopathy in Euro-Brazilian type 2 diabetic patients: relationship with polymorphisms in the aldose reductase, the plasminogen activator inhibitor-1 and the methylenetetrahydrofolate reductase genes. Diabetes Res Clin Pract 2003; 61: 133-136.

13. Gerdes LU, Klausen IC, Sihm I, Faergeman O. Apolipoprotein E polymorphism in a Danish population compared to findings in 45 other study populations around the world. Genet Epidemiol 1992; 9: 155-167.

14. Oliveira JR, Lima Filho J L, Shimokomaki CM, Okuma M, PassosBueno MR, Zatz M, et al. The use of apolipoprotein $E$ genotype for preclinical detection of risk's group for Alzheimer's disease. Am J Med Genet 1997; 74: 216-217.

15. Souza DR, de Godoy MR, Hotta J, Tajara EH, Brandao AC, Pinheiro $J \mathrm{~S}$, et al. Association of apolipoprotein E polymorphism in late-onset Alzheimer's disease and vascular dementia in Brazilians. Braz J Med Biol Res 2003; 36: 919-923.

16. Liberopoulos E, Siamopoulos K, Elisaf M. Apolipoprotein E and renal disease. Am J Kidney Dis 2004; 43: 223-233.

17. Shcherbak NS. Apolipoprotein E gene polymorphism is not a strong risk factor for diabetic nephropathy and retinopathy in type I diabetes: case-control study. BMC Med Genet 2001; 2: 8.

18. Tarnow L, Stehouwer CD, Emeis J J, Poirier O, Cambien F, Hansen $B V$, et al. Plasminogen activator inhibitor-1 and apolipoprotein $\mathrm{E}$ gene polymorphisms and diabetic angiopathy. Nephrol Dial Transplant 2000; 15: 625-630.

19. Santos A, Salguero ML, Gurrola C, Munoz F, Roig-Melo E, Panduro $A$. The epsilon4 allele of apolipoprotein $E$ gene is a potential risk factor for the severity of macular edema in type 2 diabetic Mexican patients. Ophthalmic Genet 2002; 23: 13-19.

20. Krieger $\mathrm{H}$, Morton NE, Mi MP, Azevedo E, Freire-Maia A, Yasuda N. Racial admixture in north-eastern Brazil. Ann Hum Genet 1965; 29: 113-125.

21. American Diabetes Association. Diagnosis and classification of diabetes mellitus. Diabetes Care 2004; 27: S5-S10.

22. American Academy of Ophthalmology. Diabetic Retinopathy Disease Severity Scale. American Academy of Ophthalmology. http:// www.aao.org/education/library/recommendations/international_ dr.cfm; 2005.

23. Miller SA, Dykes DD, Polesky HF. A simple salting out procedure for extracting DNA from human nucleated cells. Nucleic Acids Res
1988; 16: 1215

24. Frosst $P, B$ lom HJ , Milos R, Goyette $P$, Sheppard CA, Matthews RG, et al. A candidate genetic risk factor for vascular disease: a common mutation in methylenetetrahydrofolate reductase. Nat Genet 1995; 10: 111-113.

25. Crook R, Hardy J, Duff K. Single-day apolipoprotein E genotyping. J Neurosci Methods 1994; 53: 125-127.

26. Kullberg CE, Arnqvist HJ. Good blood glucose control characterizes patients without retinopathy after long diabetes duration. Diabet Med 1995; 12: 314-320.

27. Klein R. Hyperglycemia and microvascular and macrovascular disease in diabetes. Diabetes Care 1995; 18: 258-268.

28. Ray D, Mishra M, Ralph S, Read I, Davies R, Brenchley P. Association of the VEGF gene with proliferative diabetic retinopathy but not proteinuria in diabetes. Diabetes 2004; 53: 861-864.

29. Franco RF, Araujo AG, Guerreiro J F, Elion J , Zago MA. Analysis of the $677 \mathrm{C} 677 \mathrm{~T}$ mutation of the methylenetetrahydrofolate reductase gene in different ethnic groups. Thromb Haemost 1998; 79: 119121.

30. Gaspar DA, Matioli SR, de Cassia PR, Araujo BC, Alonso N, Wyszynski $D$, et al. Maternal MTHFR interacts with the offspring's $B C L 3$ genotypes, but not with TGFA, in increasing risk to nonsyndromic cleft lip with or without cleft palate. Eur J Hum Genet 2004; 12: $521-526$.

31. Maeda M, Yamamoto I, Fukuda M, Nishida M, Fujitsu J, Nonen S. Diabetic retinopathy possibly results from poor blood sugar control associated with MTHFR gene polymorphism in type 2 diabetic patients: response to Yoshioka et al. Diabetes Care 2003; 26: 1948.

32. Smith JD. Apolipoprotein E4: an allele associated with many diseases. Ann Med 2000; 32: 118-127.

33. Liu L, Xiang $K$, Zheng $T$, Zhang R, Li M, Li J. Co-inheritance of specific genotypes of HSPG and ApoE gene increases risk of type 2 diabetic nephropathy. Mol Cell Biochem 2003; 254: 353-358.

34. Araki S, Koya D, Makiishi $T$, Sugimoto $T$, Isono $M$, Kikkawa $R$, et al. APOE polymorphism and the progression of diabetic nephropathy in Japanese subjects with type 2 diabetes: results of a prospective observational follow-up study. Diabetes Care 2003; 26: 2416-2420.

35. Chowdhury TA, Dyer PH, Kumar S, Gibson SP, Rowe BR, Davies $\mathrm{SJ}$, et al. Association of apolipoprotein epsilon2 allele with diabetic nephropathy in Caucasian subjects with IDDM. Diabetes 1998; 47: 278-280.

36. E to M, Horita K, Morikawa A, Nakata H, Okada M, Saito M, et al. Increased frequency of apolipoprotein epsilon 2 allele in non-insulin dependent diabetic (NIDDM) patients with nephropathy. Clin Genet 1995; 48: 288-292.

37. Reznik $Y$, Pousse $P$, Herrou M, Morello R, Mahoudeau J, Drosdowsky MA, et al. Postprandial lipoprotein metabolism in normotriglyceridemic non-insulin-dependent diabetic patients: influence of apolipoprotein E polymorphism. Metabolism 1996; 45: 63-71.

38. Dallongeville J, Tiret L, Visvikis $S, O$ 'R eilly DS, Saava M, Tsitouris $G$, et al. Effect of apo E phenotype on plasma postprandial triglyceride levels in young male adults with and without a familial history of myocardial infarction: the EARS II study. European Atherosclerosis Research Study. Atherosclerosis 1999; 145: 381-388.

39. Kreisberg RA. Diabetic dyslipidemia. Am J Cardiol 1998; 82: 67U$73 U$. 